See Article page 1133.

\section{Commentary: A thousand eyes and one: Reviewing cardiothoracic surgery educational research 2018-2019}

\author{
Nkem Azikem, MD, and Frederick A. Tibayan, MD
}

Research pertaining to cardiothoracic surgery education is, by any measure, a broad topic and difficult to follow. Each year, scores of important advances are published in at least a dozen education and specialty-specific journals, or presented in as many meetings at well more than a hundred sessions. Like the three-eyed raven in the series by George R. R. Martin, one would need "a thousand eyes and one" to keep abreast. ${ }^{1}$ Nevertheless, ideas at the forefront of cardiothoracic surgery education direct the field by influencing both faculty and fellows.

Hunt and colleagues ${ }^{2}$ provide an excellent overview of the highlights and trends in cardiothoracic surgery education during the past year. They scoured the past year's journals and meetings for the best of the best in peer reviewed work focusing on initiatives and advances in cardiothoracic surgery education. This article updates the 2017-2018 summary of the state of cardiothoracic surgery education published by the same group, ${ }^{3}$ allowing consistency in methodology and an opportunity to follow-up on predicted trends. As in the prior review, simulation, burnout, and fostering interest in medical students and residents emerge as crucial topics studied with increasingly validated tools. Hunt and collagues ${ }^{2}$ call attention to 2 areas relatively new to cardiothoracic surgery education research that will certainly influence cardiothoracic surgery and training at every level: unconscious bias and the use of social media in education.

\footnotetext{
From the Division of Cardiothoracic Surgery, Department of Surgery, Oregon Health \& Science University, Portland, Ore.

Disclosures: The authors reported no conflicts of interest.

The Journal policy requires editors and reviewers to disclose conflicts of interest and to decline handling or reviewing manuscripts for which they may have a conflict of interest. The editors and reviewers of this article have no conflicts of interest.

Received for publication April 21, 2020; accepted for publication April 23, 2020; available ahead of print May 1, 2020.

Address for reprints: Frederick A. Tibayan, MD, Division of Cardiothoracic Surgery, Department of Surgery, Oregon Health \& Science University, 3181 SW Sam Jackson Park Rd, MC: L353, Portland, OR 97239 (E-mail: tibayan@ohsu.edu).

J Thorac Cardiovasc Surg 2020;160:1138 $0022-5223 / \$ 36.00$

Copyright $(9) 2020$ Published by Elsevier Inc. on behalf of The American Association for Thoracic Surgery

https://doi.org/10.1016/j.jtcvs.2020.04.070
}

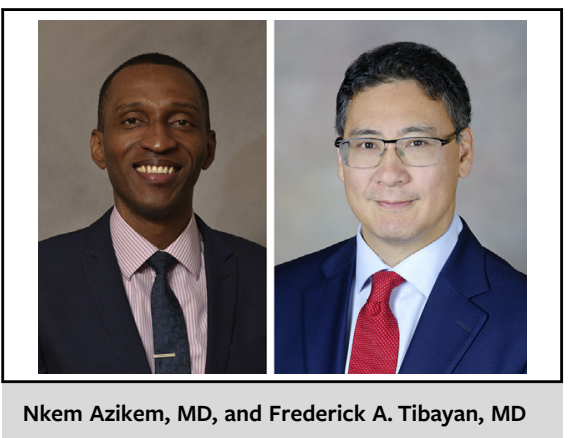

CENTRAL MESSAGE

The ideas and concepts driving

research in cardiothoracic sur-

gery education continue to

evolve and shape the specialty.

The Milestones 2.0 project, to be implemented by training programs in the coming year, will affect not only residency accreditation, but also our understanding of the core competencies to be acquired by trainees. ${ }^{4}$ As they keep their many eyes on the past, present, and future of this varied field, forthcoming work by this team should draw attention to, and perhaps predict, the overall direction of cardiothoracic surgery education.

Readers may use this article as a brief summary, as a jumping-off point for a deeper dive into an area of particular interest, or as guide to where the field is going with an eye toward contributing original work. Whatever the purpose, all are encouraged to explore this summary of topics that are shaping the next generation of cardiothoracic surgeons.

\section{References}

1. The Children. Game of Thrones. Season 4, episode 10. HBO; June 15, 2014.

2. Hunt F, Giuliano K, Etchill E, Yang SC. Cardiothoracic surgery educational research and training innovation a review of 2018-2019. J Thorac Cardiovasc Surg. 2020;160:1133-7.

3. Hunt MF, Zhou X, Lui C, Yang SC. Educational research and training innovation in cardiothoracic surgery: a year in review. J Thorac Cardiovasc Surg. 2019;157: $1722-7$.

4. Mitzman B, Beller J, Edgar L. Thoracic surgery milestones 2.0: rationale and revision. J Thorac Cardiovasc Surg. March 31, 2020 [Epub ahead of print]. 